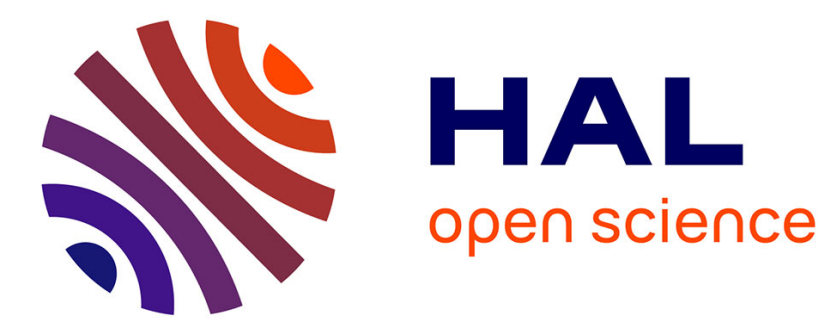

\title{
Switching costs in competitive health insurance markets
}

Karine Lamiraud

\section{To cite this version:}

Karine Lamiraud. Switching costs in competitive health insurance markets. 2013. hal-00808420

\section{HAL Id: hal-00808420 \\ https://essec.hal.science/hal-00808420}

Preprint submitted on 5 Apr 2013

HAL is a multi-disciplinary open access archive for the deposit and dissemination of scientific research documents, whether they are published or not. The documents may come from teaching and research institutions in France or abroad, or from public or private research centers.
L'archive ouverte pluridisciplinaire HAL, est destinée au dépôt et à la diffusion de documents scientifiques de niveau recherche, publiés ou non, émanant des établissements d'enseignement et de recherche français ou étrangers, des laboratoires publics ou privés. 


\title{
Switching Costs in Competitive Health Insurance Markets
}

\author{
Research Center \\ ESSEC Working Paper 1305
}

2013

Karine Lamiraud 


\title{
Switching costs in competitive health insurance markets
}

\author{
Karine Lamiraud \\ ESSEC Business School, Paris, France \\ THEMA, University of Cergy Pontoise, France
}

\begin{abstract}
In this paper we investigate the possible presence of switching costs when consumers are offered the opportunity to change their basic health insurance provider. We focus on the specific case of Switzerland which implemented a pure form of competition in basic health insurance markets. We identify several barriers to switching, namely choice overload, status quo bias, the possession of supplementary contracts for enrollees in bad health, firm's pricing strategies based on providing low price supplementary products, poor regulation of reserves and the limitations of the previous risk-equalization mechanism which left room for risk selection practices.
\end{abstract}

Dans ce papier, nous analysons la présence de coûts de changement (coûts de switching) lorsque les consommateurs ont la possibilité de changer d'assureur pour l'assurance maladie de base. Nous nous intéressons au cas de la Suisse qui a mis en place une forme relativement pure de concurrence en assurance maladie. Nous identifions différents types de coûts de changement : l'excès de choix (en termes de nombre de compagnies présentes sur le marché), le biais de statu quo, la possession d'un contrat d'assurance supplémentaire pour les assurés déclarant un mauvais état de santé, les stratégies tarifaires des firmes qui utilisent l'assurance supplémentaire comme produit d'appel, la mauvaise régulation des réserves des caisses et les limites liées au mécanisme initial de compensation des risques.

\section{Keywords}

Brand loyalty, Choice overload, Competition among health insurers, Status quo bias, Supplementary health insurance, Switching costs, The Swiss case 


\section{Introduction}

Many European countries have social health insurance where citizens cannot choose between different providers for basic coverage. Although Germany and the Netherlands, have only recently introduced policies giving citizens the freedom to choose their own health plan, this has been a long standing feature of the Swiss healthcare model. The assumption is that competition to obtain consumers puts insurance providers under pressure to increase service quality and/or decrease premiums. As for any market however, competition in health insurance only works if the threat of consumers "voting with their feet" is credible. In other words, it only works if enough consumers switch to more competitive insurers.

In this paper we investigate the possible presence of switching costs when consumers are offered the opportunity to change their basic health insurance carrier. We focus on the specific case of Switzerland as this country, through its pure form of competition and the period of time which has elapsed since this system was implemented, offers one of the best settings to study competition in basic health insurance markets.

The paper is organized as follows. Following this introduction, Section 2 provides some insights into the general theory on switching costs. Section 3 describes the features of managed competition in basic health insurance in Switzerland. Section 4 highlights the persistence of huge premium differences within Swiss cantons, which may be explained by low switching rates. Section 5 explores possible switching barriers. Section 6 concludes and suggests ways of improving the current system through reducing switching costs.

\section{Switching costs}

In many markets, consumers incur costs when switching from one supplier to another. These costs are called switching costs (barriers).

Categories of switching costs include those caused by: transaction costs of switching suppliers (e.g. monetary costs and time lost due to necessary paperwork when switching to a new provider); uncertainty about the quality of untested brands; psychological costs such as "brand loyalty"; discount strategies implemented by the current provider; shopping costs when consumers buy several products from the same provider. Switching costs may also be related to search costs.

In a market with switching costs, the rational consumer will not switch to the supplier offering the lowest price if the switching costs (in terms of monetary cost, effort, time, uncertainty, and other elements) outweigh the price differential between his/her current supplier and the new one. If this happens, the consumer is said to be locked-in to the current supplier. If a supplier manages to lock-in consumers in this way, it may raise prices to a certain point without fear of losing these customers. However, the incentive to do so must be balanced with the incentive to set a lower price to attract new customers. 
Despite this second incentive, the first situation is expected to dominate. Switching costs often do raise average prices in competitive markets compared with competitive markets without switching costs. The possible consequence of this is that consumers may be worse off. Accordingly, policy intervention to reduce switching costs may be appropriate.

Empirical studies highlight the importance of switching costs for a wide range of markets including credit cards, cigarettes, computer software, supermarkets, air travel, phone services, online brokerage services, electricity suppliers, and automobile insurance. In this paper we investigate the presence of switching costs in basic health insurance markets. Empirical evidence from the Swiss context serves to illustrate several types of switching costs presented above.

\section{Managed competition in Switzerland: the regulatory framework}

Switzerland (population 7.8 million in 2009) is divided into 26 cantons, each canton being responsible for the organization of its own health care system. Overall health care is regulated by the Federal Law on Social Health Insurance (LAMal), which has been in force since 1996 after its ratification in a popular referendum in 1994.

The main regulatory features of Swiss health insurance markets are described below.

(1) An individual mandate requires all residents to have health insurance coverage. Individuals must take up insurance within their canton of residence. Each family member must contract on an individual basis. Health insurance cannot be provided by an employer as a fringe benefit and so the premium is paid in full by the insurance enrollee, a situation which should make the latter very reactive to differences in premium. Cantons are given the responsibility for ensuring that every resident receives coverage. The threat of lawsuits ultimately enforces the individual mandate in cases of non-compliance.

(2) The law defines a standardized benefit package in order to avoid competition on content of coverage. Hence all insurance companies must reimburse the same basket of goods. While small variations may exist in the quality of services provided (e.g. different reimbursement timeframes), these are minimal in nature and do not call into question the characteristics that the same product has to be offered by various providers. The level of cost sharing is also defined by law and is invariable across insurers (see box 1).

(3) The law authorizes full freedom in terms of choosing one's primary physician as well as unlimited access to specialists. Physicians are paid on a fee-for-service basis. However enrollees can voluntarily opt for contracts with limited choice of physicians and those physicians who provide services within such contracts are paid on a per-capita basis (see point 4 below).

(4) Premiums charged by companies to consumers are community-rated (see glossary). This means that while they can differ between health plans an insurer must offer uniform premiums to people who meet all three of the following criteria: same age group (0-18, 19-25 and >25), same geographic area, and same type of coverage. With regard to geographic areas, there are 78 pricing areas, i.e. 3 per canton. Nevertheless, for a given company, prices turn out to be very similar between the three price areas within the same canton. Hence we can consider that there are effectively 26 areas of price competition. With regard to the type of coverage, three types of basic health insurance coverage are available: all companies must offer a contract with a low deductible which guarantees access to any physician; they can also offer contracts with higher deductibles (see box 1) and/or contracts with a limited 
choice of physicians. In 2008 the most frequent choice by enrollees was a 300 CHF deductible health insurance policy (38.7 percent), followed by plans with higher deductibles (31.2 percent). Insurance covering a limited choice of providers (Health Maintenance Organizations -HMO- contracts) accounted for 30.0 percent of enrollees. This latter figure reflects HMOs recently increasing market share, given that only $8.2 \%$ of enrollees held HMO-contracts in 2003.

Note that premiums paid by enrollees are neither risk nor income-related. Clients on low-incomes receive subsidies from their canton of residence. In 2008, the mean yearly subsidy was 1511 CHF per subsidized enrollee.

(5) A risk equalization mechanism is enforced at the cantonal level (see box 1) so that funds with a higher percentage of bad risks are compensated in comparison with those with a higher percentage of good risks and in order to avoid risk selection practices by health insurers (see glossary).

(6) Health insurers must accept every application for basic insurance.

(7) Enrollees can switch companies twice a year, in June and December.

Finally, there is clear regulatory separation between basic and supplementary coverage. For healthcare services not included in the basic benefit package, an individual may subscribe to contracts for supplementary coverage, which cover, for example, dental care, private or semi-private hospital rooms, cross-border care and alternative medicine. Supplementary insurance is regulated by the Insurance Contract Law, which allows risk selection by companies and does not impose any constraint on the coverage supplied. Basic and supplementary insurance can be purchased from two different insurers or from the same insurer.

These features suggest that freedom of choice in terms of choosing one's insurer is very much encouraged by the regulatory framework and in particular that changing health insurers for basic coverage involves very low quality-related or transaction-type switching costs. Indeed, basic insurance coverage is virtually identical from one health insurer to the next, and generally the enrollee can remain with the same physician or hospital regardless of insurer. Furthermore, the switching procedure is simple: the individual must write a letter to their health insurer, the templates for which are freely available on well-known websites. Also, search costs are low. All premiums are published officially every year by the Federal Office for Public Health and distributed to households that request them. Furthermore, the most competitive premiums can be easily found on the Internet and in newspapers.

If we look at the market structure, we can see that enrollees have a great deal of choice. Although the number of health insurers (all non-profit) offering mandatory health care insurance in Switzerland decreased between 1996 and 2008 (145 and 86 authorized health insurers respectively), the choice set faced by each consumer has increased since the LAMal was implemented. In 1996 the mean number of health plans per canton was 39. Consumers could choose from more than 40 health plans in only two cantons. The mean number of health plans per canton rose to 57 in 2006, varying between 50 and 69 choices. 


\section{Stylized facts: the ineffectiveness of competition to date}

In a health insurance market like the Swiss one, with its community-rated premiums for each health plan, homogenous benefits, open enrollment and a large choice of insurers, one would expect strong price competition within each area of competition, resulting in small premium differences across plans and, in turn, cost-containment or at least a moderation in premium increases.

However the observed facts are very different. Premiums have continued to rise. In 1997 the price index for an adult basic health insurance contract was 92.3. It increased to 100 in 1999 and 142.1 in 2008. Furthermore there is a great deal of variability across firms in premiums within a given canton, as suggested by the box plots of monthly premiums displayed in Figure 1. For example, in 2011 in the Geneva canton, the difference between the least and the most expensive yearly premiums equaled 1665 Swiss Francs, a difference of $39 \%$, for an adult contract with the lowest deductible, which is very large considering it is only for one family member. Moreover, the within-canton variance has remained quite stable over time. Hence, moderation in premium increases has not occurred and premiums have not converged.

Competitive health care plans cannot be held responsible for the increase in premiums. The rise in premiums mostly mirrors the rise in health care costs. Indeed health care costs represent a very high percentage of premiums ${ }^{1}$ and premiums are highly correlated to health care costs in each canton, with Pearson and Spearman correlation coefficients close to 1 . The increase in health care expenditures in Switzerland can be largely accounted for by an increase in wealth and in technological developments. It may also be related to patient behaviors including the moral hazard effect (i.e. overconsumption because of guaranteed coverage) and physician behaviors (e.g. incentives to increase the volume of care in the fee-for-service payment system). However, the moral hazard effect is not specific to private health insurance systems, such as the Swiss one. Public insurance systems can also be affected. Furthermore, as suggested above, competitive health plans in Switzerland do not have the means to control health care expenditures from the supply side. In particular they cannot define modes of payments for physicians or implement selective contracting except in HMO options, which have recently started gaining market share. Hence, competitive health care plans cannot be held responsible for the increase in health care expenditures.

In contrast, the lack of premium convergence may be related to the ineffectiveness of competition, and one important factor for this is low switching rates. In Switzerland, annual switching percentages are low despite existing price differentials for identical benefit packages. Health plan switching rates only averaged approximately 3\% between 1997 and 2007, ranging from 2\% to 5\%.

We are now going to investigate the barriers to switching in the Swiss basic health insurance market.

${ }^{1}$ Administrative costs are quite low and represent around 6\% of collected premiums. 


\section{Possible barriers to switching behaviors}

How can low switching rates be explained?

Given the fact that price information is widely available and that there would seem to be substantial opportunities to take advantage of lower premiums for what appear to be homogeneous health plans, we begin by considering how the standard market model addresses consumer choice. The model assumes that, under uncertainty, the expected utility of customers will be maximized. Given a set of $N$ choices, an individual will choose a health plan if its expected utility is greater than that of each of the alternatives. After choosing a plan, a consumer may experience a change in health state or other personal circumstances (e.g. reduced income) or face a new set of premium choices due to new health plans entering the market. The new circumstances may cause the individual to reassess the expected utility of their current health plan in light of alternatives, with the result that they may switch.

Since the implementation of LAMal in Switzerland, the size of the choice set in local markets has grown (see section 2) and the set of plans offering the cheapest premiums for basic insurance has continued to change. Hence, low switching rates may be explained by switching costs.

As already mentioned, the most obvious type of switching costs, i.e. transaction-type and quality-related switching costs, can be ruled out in the Swiss context. Consequently others need to be considered. We will now investigate the following three main types of switching costs: psychological switching costs, switching costs related to the multiproduct environment and switching costs related to regulatory features.

\subsection{Psychological switching costs}

\subsubsection{Choice overload}

Research in economics and psychology consistently brings up the issue of whether greater choice is always in the consumer's interest, the argument being that too much choice may inhibit consumers from making any choice.

Two underlying forces may explain such a phenomenon. First, the information or cognitive overload theory argues that, as the choice set grows, the cost of the individual's information processing increases. This happens if individuals continue to consider all alternatives as the choice set expands. Even if consumers use shortcuts (eliminating the worst alternative, for example) information processing costs grow with the choice set. This leads to the hypothesis that consumers can be overwhelmed by "too great a choice”. The result is an inverted U relationship between the size of the choice set and the quality of decision-making.

The second psychological force concerns the fear of making an incorrect choice or subsequent regret in situations where decision-making is complex, consequential and uncertain. One response to such decision-making circumstances, observed in both experimental and observational studies, is a tendency toward decision avoidance either by opting for the status quo or by walking away from the decision entirely. 
In the Swiss health insurance context, the large number of competing health plans may result in information overload, even though individual health plans can be easily assessed. Frank and Lamiraud (2009) provide some support for this phenomenon. A survey focusing on individuals' health plan choices in Switzerland together with market price data were used to study the factors associated with the probability of switching and, in particular, to investigate the impact of the number of available plans on the probability of an individual switching. The results showed a monotonically decreasing likelihood of switching with increasing choice. Cantons with more choices had significantly lower switching rates ceteris paribus. Furthermore, it was demonstrated that consumers consider all health insurance companies, including fringe players (i.e. companies with small market shares) when deciding about insurance cover. These results are consistent with the inertia in decision making associated with choice overload.

\subsubsection{Status quo bias}

Consumer attachment to the status quo (status quo bias) could also account for low switching rates. This has been associated with a tendency to exaggerate the disadvantages of leaving one's current situation and to understate the potential gains of switching, in an environment of uncertainty and complex decision-making.

Three results highlighted by Lamiraud and Frank (2009) provide further evidence of the existence of a status quo bias in Swiss health insurance markets. First, people with longer periods of attachment to a particular health plan were less likely to express their intention to switch plans. Second, people making new health plan choices (switchers, and those new to the market) chose to enroll in a different set of health plans from those who had not switched for some time. Third, survey respondents explicitly reported that their decision not to change their health plan was out of habit or because they were satisfied with their policy.

\subsection{Switching costs generated by the multiproduct environment}

Another possible barrier to switching behavior is the relationship between basic and supplementary insurance.

Although a clear regulatory separation exists between basic and supplementary insurance in Switzerland, in reality both types of insurance coverage are strongly linked: companies are allowed to operate both in basic and supplementary markets and most individuals subscribe to the same provider for both. Of the $88 \%$ of enrollees who took out supplementary coverage in 2007 , only $9 \%$ subscribed to different companies for their basic and supplementary contracts.

To analyze the interaction between basic and supplementary insurance, we have to consider two characteristics of the Swiss health insurance market. First, there are additional costs when a client's basic and supplementary contracts are with different companies (e.g. separately mailed bills). Secondly, risk selection is authorized for supplementary insurance. 
Switching costs generated by the relationship between basic and supplementary insurance have been shown to originate both from the consumer (section 5.2.1) and the firm (5.2.2).

\subsubsection{Supplementary Health insurance as a barrier to switching Basic Health Insurance provider.}

Dormont et al. (2007) investigated four possible mechanisms through which holding a supplementary insurance contract may act as a barrier to switching one's basic insurance policy to another insurer.

(a) The first mechanism relies on a "pure switching cost effect". Given that subscribing to basic and supplementary contracts with two different insurers induces administrative costs, those planning to switch may have to consider moving both their basic and supplementary contracts: this is more burdensome than a single switch.

(b) The second mechanism refers to selection practices in the supplementary insurance market, and to consumer beliefs about the existence of such a policy. Take for example a customer who thinks that he/she is a "bad risk" and believes that insurers reject applications for supplementary insurance contracts from individuals considered as such. Currently holding a supplementary insurance contract would then act as a barrier to him/her switching basic insurance. Indeed, the new insurer may reject the application for a supplementary contract or propose an intentionally unacceptable offer (e.g. very high premiums).

The third and fourth mechanisms ( $c$ and $d$ below) refer to selection practices in basic health insurance markets (see footnote 11). In such cases, there is an incentive for insurers to retain enrollees who hold supplementary contracts and drop the others.

(c) Mechanism c is simply based on the fact that regulation for supplementary insurance is less restrictive. Lack of contract standardization may lead to less competition and profits may be realized from selling supplementary insurance contracts. In this context, profitmaximizing insurers would have an incentive to retain supplementary contract purchasers.

(d) Mechanism d is based on the assumption that holding a supplementary insurance contract might be correlated with being a "good risk" vis-à-vis basic insurance, i.e. having a lower probability of consumption in basic insurance for a given illness. This conjecture might be relevant for supplementary insurance covering alternative medicine:

individuals who subscribe to such contracts may be more reluctant to consume "standard" health care, especially drugs, covered by the basic insurance. This might also be true for other kinds of supplementary contracts, perhaps indicating the subscriber's greater attention to prevention. An insurance company can observe the use of health services by its enrollees, but the econometrician cannot: we only observe self-assessed health. If we suppose that supplementary insurance indicates that the individual is a good risk, then discovering that those with supplementary insurance and/or good health are less likely to switch, would in turn suggest that insurance providers try and succeed in retaining good risks.

Given the prohibition of risk selection in the Swiss market for basic insurance, mechanisms $(c)$ and $(d)$ raise the question of what indirect tools are available to insurers in order to retain certain enrollees. Anecdotal evidence regularly reported in newspapers suggests that some insurance companies rely on such commercial practices as offering discounts on sports items or events. 
In order to disentangle these four possible mechanisms, Dormont et al. (2009) assessed to what extent the influence of supplementary contracts on switching rates depends on the enrollee's health status. For $(a)$ and $(c)$ to be true, the effect of supplementary contracts on switching rates would have to be unrelated to the individual's self-assessed health. For $(b)$ to be true, holding supplementary insurance would have to act as a barrier to switching for those in poor health. For $(d)$ to be true, holding supplementary insurance would have to act as a barrier to switching for those in good health.

Controlling for relevant covariates, Dormont et al. (2009) show that holding a supplementary contract reduces the probability of switching in basic insurance for those in poor self-assessed health but has no effect on the switching behavior of enrollees in good/very good health. These empirical findings suggest that the main mechanism at work is (b): if the customer thinks he/she is a bad risk and believes that insurers reject applications for supplementary contracts from individuals considered as such, he/she might refrain from switching basic insurance provider. This effect, identified through survey data covering the period following the implementation of the reform (1997-2000), was confirmed by behaviors observed over 2003-2007 (Dormont et al., forthcoming).

\subsubsection{Pricing strategies}

Lamiraud and Stadelman (2011) examine the relationship between basic and supplementary health insurance from a different angle. They analyze firms' pricing strategies (i.e. pricing of basic and supplementary products) as a way of reinforcing consumer inertia. In particular they investigate whether firms use bundling strategies or supplementary products as low price products in order to capture consumers. Bundling is the sale of two or more products in a package (i.e. one basic contract and one supplementary contract). The bundle comes at a discount with respect to the total price of the individual goods when sold separately. Another strategy consists in establishing a low price for a product in order to attract customers who are likely to buy other products at regular or high prices.

Lamiraud and Stadelmann (2011) do not show any evidence of bundling in the Swiss setting. They do however show that firms use low price supplementary products to lock in consumers. A majority of firms price one of their products at a low price. None offer cheap products overall (i.e. in both basic and supplementary markets). Low price insurance products differ across companies. When buying a low price supplementary product consumers always buy their basic contract from the same firm. Furthermore those who opt for low price supplementary products are less likely to declare an intention to switch basic insurance companies in the near future. This latter result is true for each level of risk category.

Hence pricing strategies seem to generate additional barriers to switching basic insurance provider, thereby reinforcing consumer inertia. 


\subsection{Switching costs generated by the regulatory features}

Another possible barrier to switching behaviors is that some regulatory features may tend to attenuate competition in the basic health insurance market. We will focus on the rules for building reserves and the risk equalization mechanism.

Health insurers are legally obliged to build reserves in order to protect against unpredictable financial risks associated with unforeseen catastrophic events, such as epidemics. Depending on their size, insurance companies are required to keep between $10 \%$ and $20 \%$ of collected premiums in reserve. Reserves per enrollee are not transferable to another company. Hence, if a subscriber leaves one insurance provider, his/her reserves stay with that provider. Consequently that fund becomes richer whereas the new one is impoverished by the new entrant. The result is that a firm which attracts many new enrollees during a given year (because of low prices) would mechanically have to increase its premium the following year in order in order to start creating reserves. If a client expects that switching plans will ultimately induce a subsequent rise in premiums (due to the building of reserves as the individual expects that the low price plan will attract a lot of new consumers), then the expected utility of switching becomes lower and this may induce consumer inertia. Hence the rules obliging reserves creation may result in market failure.

Poor regulation in terms of the previous risk-equalization mechanism (see box 1) may have also induced low switching rates. When only age and gender were used as risk adjusters, the incentives for companies to practice risk selection were very strong. There was an incentive for insurance firms to try to avoid insuring unhealthy young people while retaining healthy older enrollees. If such risk selection practices existed, they may have represented an additional barrier to switching and consequently may have prevented price competition from working properly.

\section{Conclusions}

Switzerland has implemented a relatively pure form of healthcare competition in which a great degree of free choice has been provided to the consumer. Nevertheless, the persistence of great variations within cantons in terms of insurance premiums, together with low switching rates, raises the question about the effectiveness of competition in Switzerland in the basic insurance market. We identified several barriers to switching, namely choice overload, status quo bias, the possession of supplementary contracts for enrollees in bad health, firm's pricing strategies based on providing low price supplementary products, poor regulation of reserves and the limitations of the previous riskequalization system which left room for profitable risk selection practices.

Do such inefficiencies imply that competition should be replaced by a single health insurance scheme? A referendum was held on such a proposal in 2007. It called for a merger of the existing 87 health insurance companies. Final results showed that $71 \%$ of voters opposed the reform. This vote demonstrated that the Swiss preferred the current system.

The analysis provided in section 5 suggests some ways of improving the current system. 
First, evaluating an optimal number of insurance companies in the market may be useful, as the results suggest that having too great a choice effectively inhibits switching between health plans. Furthermore, economic analysis tells us that having a limited number of firms may be enough to achieve effective competition. Nevertheless, one would first need to assess whether, from a supply point of view, having a high number of firms induces each insurance company to achieve better efficiency.

Second, reforming the regulation of supplementary insurance could be an option. Our analysis illustrates that consumer choices for basic and supplementary health plans are not independent from each other. Although both types of insurance markets are regulated by two different laws and supervised by two different institutions, they are closely linked. Managed competition in the basic insurance market may suffer from a lack of adequate regulation in its supplementary counterpart. The two main policy options are either to separate these two markets more effectively (i.e. preventing firms from being active in both markets) or to regulate the supplementary insurance market differently, in particular by preventing risk selection.

Third, there is probably room for improvement in the current regulation. Reserves could follow the individual when s/he switches.

In this paper we have focused on Switzerland. Large Premium variation and consumer inertia rates have also been highlighted in the Netherlands, which implemented a system sharing many features of the Swiss one in 2006. Since 2006, switching rates have been reported to be low in the Netherlands. It has also been found that the possibility for switching for bad-risk individuals in the basic insurance market is substantially reduced by the presence of supplementary insurance.

\section{7. $\quad$ Further reading}

Farrell and Klemperer (2007) provide valuable overviews on the literature of consumer switching costs.

Switching costs in Swiss health insurance markets were investigated by Frank and Lamiraud (2009), Dormont et al. (2009), Lamiraud and Stadelmann (2011), Dormont et al. (forthcoming).

Data concerning the Swiss health insurance markets come from various sources. Premiums are published officially every year by the Federal Office for Public Health. Information on consumer health plan choices was collected by two surveys. The OFAS survey was carried out in 2001 and can be obtained from the Swiss Information and Data Archive Service (SIDOS). A follow-up survey was carried out in 2007 by the University of Lausanne under the supervision of Brigitte Dormont, Pierre-Yves Geoffard and Karine Lamiraud who wrote the questionnaire. 


\section{References}

Dormont B, Geoffard PY, Lamiraud K (2009). The influence of supplementary health insurance on switching behaviour: evidence from Swiss data. Health Economics 18(11): 1339-1356.

Dormont B, Geoffard PY, Lamiraud K. Assurance maladie en Suisse : l'assurance supplémentaire nuit-elle à la concurrence sur l'assurance de base ? Economie et Statistiques, forthcoming.

Farrell J, Klemperer, P (2007). Coordination and lock-in: competition with switching costs and network effects. Handbook of Industrial Organization, Volume 3, edited by M. Armstrong and R. Porter.

Frank RG, Lamiraud K (2009). Choice, Price competition and Complexity in Markets for Health Insurance. Journal of Economic Behavior and Organization 71(2): 550-562.

Lamiraud K, Stadelmann P. Strategic pricing behaviors in the presence of consumer inertia: the case of health insurance. Paper presented at the 2011 NBER Summer Institute. 
Figure 1: Box plot of adult monthly premium (for a 300 CHF deductible contract) by canton (2010)

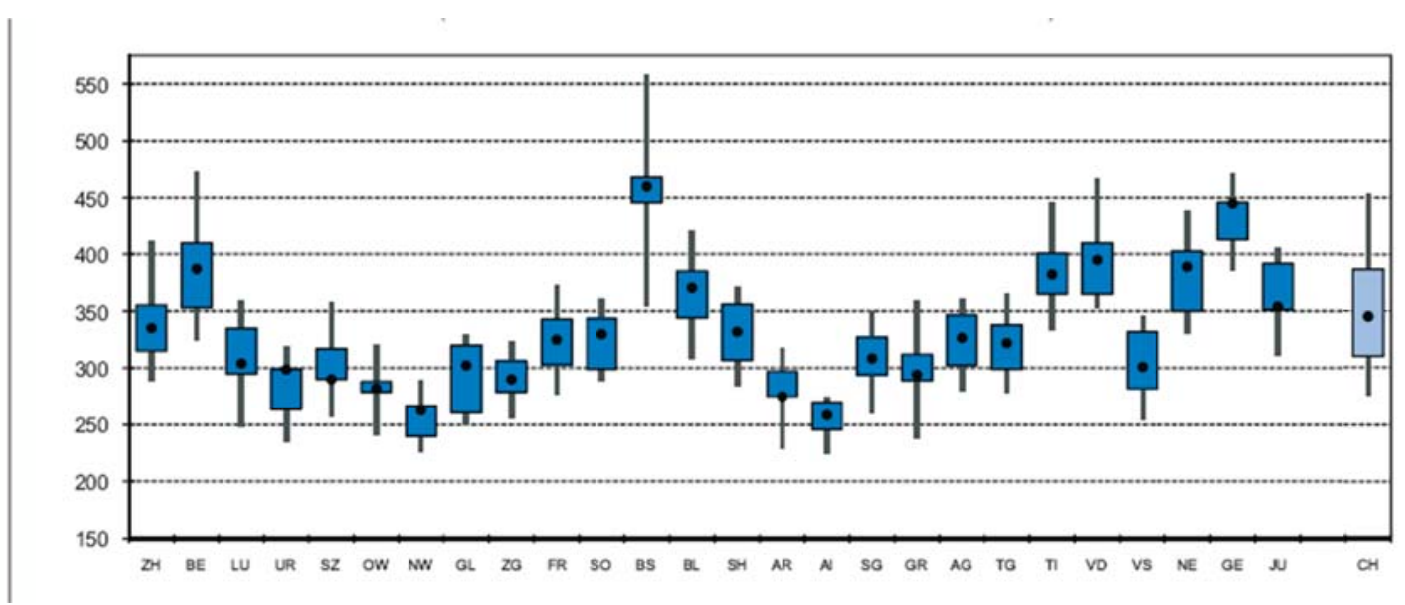




\section{Glossary}

\section{Risk selection practices in health insurance markets}

Three main types of risk selection practices exist. Dumping refers to deliberately losing the sickest clients (based on medical information for example). Cream skimming refers to attracting healthy individuals, for example through advertisement campaigns targeted at young people. Stinting occurs when a company initially tries to and then continues to keep high risk individuals away, for example by not sending application forms to older patients who ask for them.

In Switzerland risk selection may occur because of community rating: companies expect to make profits on good risks and losses on bad risks. Dumping is forbidden in Switzerland, but cream skimming and stinting may occur.

\section{Community-rated premiums}

Premiums are community-rated when, within a given insurance company and for a given type of insurance contract, they are uniform across enrollees with different health statuses.

\section{Switching costs (barriers)}

Costs incurred by consumers when switching from one supplier to another. Categories of switching costs include those caused by: transaction costs of switching suppliers (e.g. monetary costs and time lost due to necessary paperwork when switching to a new provider); uncertainty about the quality of untested brands; psychological costs such as "brand loyalty"; discount strategies implemented by the current provider; shopping costs when consumers buy several products from the same provider. Switching costs may also be related to search costs.

\section{Box 1: The Swiss system in detail}

\section{Cost-sharing arrangements}

All contracts include a deductible on yearly expenditures. Enrollees can choose from 6 possible deductible levels $(300,600,1000,1500,2000,2500 \mathrm{CHF})$. Once the deductible level has been reached enrollees pay a $10 \%$ co-insurance rate up to a maximum of $700 \mathrm{CHF}$. Hence, if the enrollee chooses a $300 \mathrm{CHF}$ deductible, then the maximum out-of-pocket amount that he or she may have to pay is $1000 \mathrm{CHF}$.

\section{Risk equalization (or risk-adjustment)}


A retrospective risk equalization mechanism is enforced by the law at the cantonal level. The "Common Institution under the Federal Health Insurance Act", a federal office, regulates the system. Risk adjustment consists in adjusting the premium by redistribution.

Until 2011, only age and gender were used as risk-adjusters. Adult policyholders were classified according to 15 age categories $(18-25,26-30, \ldots .,>91)$ and gender. Hence there were a total of 30 risk categories. The average value of costs in a given risk category was computed the end of the calendar year. The average value of costs within each canton was also determined. The difference between these two averages indicated whether health insurance funds had to pay a contribution (if the value was $<0$ ) or receive a contribution (if the value was $>0$ ). Sickness insurance funds had to pay (or receive) contributions for each policy holder belonging to the risk category concerned. For example, if the difference between the average of costs for females aged 66-70 and the average of total costs amounted to $1400 \mathrm{CHF}$ over a year in a given canton, then each insurer in this given canton would receive $1400 \mathrm{CHF}$ for each of its female enrollees aged 66-70. Note that the costs used to compute contributions are total health care costs incurred by the patient minus out-of-pocket health expenditures directly borne by the patient. Also note that the value of money transfers obtained/given back for each enrollee does not depend on whether the enrollee has opted for a low or a high deductible level.

A third risk adjuster, based on whether the enrollee had an inpatient stay (of at least 3 days) during the previous year, was adopted by parliament on the 21st December 2007, hence increasing the number of risk-adjusters to three and the number of risk categories to 60 . This change came into effect on January 1st 2012 and will be implemented at the end of 2012.

Hence an enrollee brings his/her community-rated premium to the insurer plus the riskadjusted money transfer from the"Common Institution under the Federal Health Insurance Act". The chart below illustrates this.

Money flows to health insurance companies:

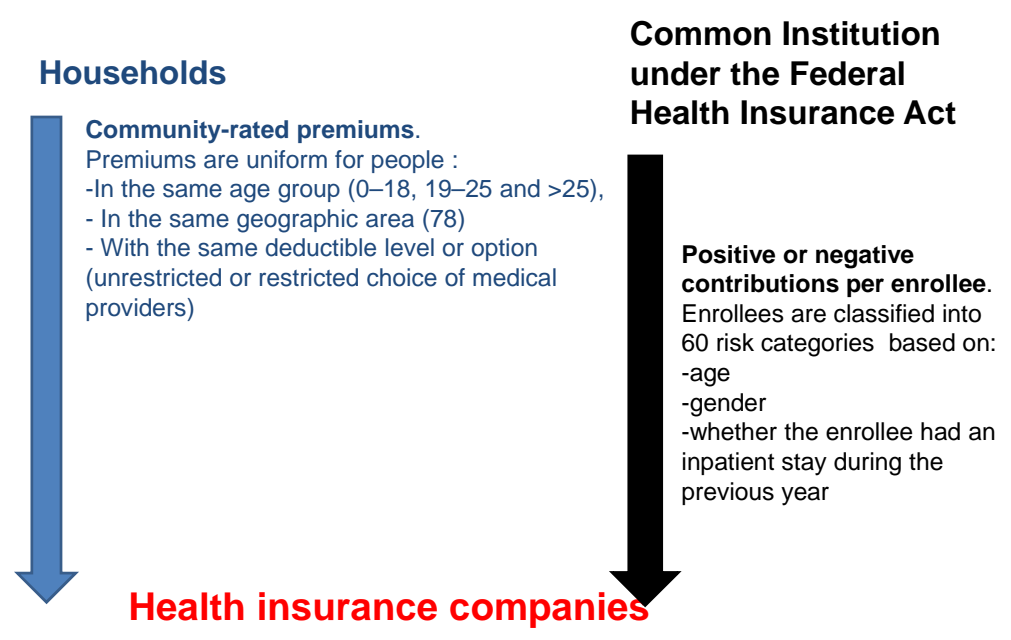


ESSEC Business School Avenue Bernard Hirsch BP 50105

95021 Cergy-Pontoise Cedex

France

Tél. +33(0)134433000

$\mathrm{Fax}+33(0) 134433001$

www.essec.fr

\section{ESSEC Executive Education} CNIT BP 230

92053 Paris-La Défense France

Têl. +33(0)146924900

Fax +33(0)1 46924990

http://formation.essec.fr

ESSEC Business School

Singapore Campus

100 Victoria Street

National Library Building \# 13-02

Singapore 188064

essecasia@essec.fr

Tél. +6568849780

Fax +6568849781

www.essec.edu

Informations

Alison Bougi

+33 (0)134433358

bougi@essec.fr

www.essec.fr

research.center@essec.fr

ISSN 1291-9616 